\title{
Trust, Partnership and Sharing
}

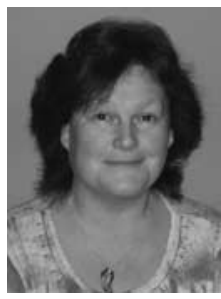

Manda Dunne

BARNA Chair

I t was my pleasure recently to attend a demonstration by a famous Californian Horse Whisperer. It really was a captivating and amazing experience that I could not have appreciated before I had witnessed some of the things I saw that day. Several horse owners had brought their horses with them, all of which had a particular problem, ranging from not being able to load into their horseboxes, to spooking at plastic bags. Some had never been able to take a rider on their back before.

The whole process begins with the horse running inside a round pen. The horse whisperer is with the horse and runs for about a quarter of a mile. This specific distance is relevant because this is how far a horse would run in the 'fright and flight' mode to escape a predator. You would then observe the horse licking and chewing as it is beginning to realise that the person there is of no threat and they would rather be with them than without them. This is when, in the wild, the herd is at its most relaxed, grazing. Then the horse drops its head towards the floor and the whisperer knows this to be the moment he can turn his shoulders away, and the horse will follow him, demonstrating 'join up'. At this point the whisperer has the horse's trust and he can now begin to understand and deal with the specific problem that horse has. $\mathrm{He}$ is starting the road map of the work that must be maintained with the animal to continue improving the situation.

I have tried to explain briefly how the trust was formed before any real progress could be made on the road to recovery. It is difficult to put this experience into words and how the horse whisperer achieves what he does, but I can say it is a moving, powerful and emotional experience. I began to think how this compares to our roles as nurses and the relationships we build with our patients. Trust is as important between nurses as it is between nurse and patient. If we are unable to trust each other, share information and build professional partnerships this must surely have a profound effect to the recovery of the patient.

The horse whisperer told us of how he had saved many a horse from an unthinkable end by gaining their trust and helping them to overcome their problems. He was prepared to take the time and use his skills to secure a safe and happy future for them. It has often been said by a patient, 'I trust the nurse, and she will look after me'. We owe it to our profession to work together as a team, trusting each other, gaining the trust from the people we care for and learning to share our knowledge and skills and support the future of nursing.

I do not wish to compare the work of a horse whisperer to that of a nurse, but quite simply to demonstrate how powerful and life changing trust, partnership and sharing can be and how this can affect our happiness, and ultimately the welfare of the patients in our care, as well as the working relationships with our colleagues. I will leave you to make your own minds up regarding what I have discussed, but most of all, I hope you have enjoyed reading it! 